\title{
Islet transplantation reverses the effects of maternal diabetes on mouse oocytes
}

\author{
Pan-Pan Cheng ${ }^{1}$, Jun-Jie Xia ${ }^{1}$, Hai-Long Wang ${ }^{2}$, Ji-Bing Chen ${ }^{2}$, Fei-Yu Wang ${ }^{1}$, Ye Zhang ${ }^{2}$, \\ Xin Huang ${ }^{1}$, Quan-Jun Zhang ${ }^{3}$ and Zhong-Quan $\mathrm{Qi}^{1}$ \\ ${ }^{1}$ Organ Transplantation Institute of Xiamen University, ${ }^{2}$ Basic Medical Department of Medical College and \\ ${ }^{3}$ The Yanwu Branch of Zhongshan Hospital, Xiamen University, Xiamen City, Fujian Province 361005, \\ People's Republic of China
}

Correspondence should be addressed to Z-Q Qi; Email: oti@xmu.edu.cn

\begin{abstract}
Maternal diabetes adversely affects preimplantation embryo development and oocyte maturation. Thus, it is important to identify ways to eliminate the effects of maternal diabetes on preimplantation embryos and oocytes. The objectives of this study were to investigate whether islet transplantation could reverse the effects of diabetes on oocytes. Our results revealed that maternal diabetes induced decreased ovulation; increased the frequency of meiotic spindle defects, chromosome misalignment, and aneuploidy; increased the relative expression levels of $\mathrm{Mad} 2$ and $\mathrm{Bub1}$; and enhanced the sensitivity of oocytes to parthenogenetic activation. Islet transplantation prevented these detrimental effects. Therefore, we concluded that islet transplantation could reverse the effects of diabetes on oocytes, and that this technique may be useful to treat the fundamental reproductive problems of women with diabetes mellitus.

Reproduction (2011) $141417-424$
\end{abstract}

\section{Introduction}

Autoimmune destruction of insulin-producing pancreatic $\beta$-cells is the main cause of type 1 diabetes mellitus. For many young women with the disease at puberty, treatment and education are often focused on long-term glycemic control to prevent microvascular damage. The sequelae of microvascular damage, including retinopathy, renal insufficiency, and peripheral neuropathy, are significant. Of equal importance is the effect of hyperglycemia on the reproductive health of women, because the oocyte and the embryo are particularly vulnerable to both acute and chronic exposure to hyperglycemia.

Women with poorly controlled type 1 diabetes often suffer from a series of reproductive problems such as miscarriage, neonatal morbidity and mortality, and congenital malformations (Sadler et al. 1988, Becerra et al. 1990, Greene 1999). Maternal hyperglycemia adversely affects the progression from the one-cell stage to blastocyst in rodent models (Diamond et al. 1989, Lea et al. 1996, Moley et al. 1998). Emerging evidence has implicated that these effects are associated with compromised oocyte maturation (Colton et al. 2002, Doblado \& Moley 2007). A decrease in the rate of germinal vesicle breakdown (GVBD; Diamond et al. 1989, Colton et al. 2002, Chang et al. 2005, Kim et al. 2007, Ratchford et al. 2007) and the number of ova at metaphase II (MII; Colton et al. 2002), both of which are markers of oocyte nuclear maturation, were observed in superovulated oocytes obtained from diabetic mice; furthermore, mitochondrial dysfunction, spindle disorganization, chromosome misalignment, and aneuploidy were observed (Goud et al. 2006, Wang et al. 2009), indicating the abnormal cytoplasmic maturation of superovulated oocytes obtained from diabetic mice. Since maternal diabetes compromises oocyte maturation and affects the subsequent embryo development, it is necessary to explore the effective ways to reduce damage to oocytes caused by diabetes.

Insulin treatment is the conventional treatment modality for type 1 diabetes. Currently, the mainstays of patient care of women with type 1 diabetes who are seeking pregnancy involve close monitoring and glucose control through dietary modifications and insulin treatment (Gabbe \& Graves 2003). Even though improvements in glycemic control throughout pregnancy have drastically reduced the incidence of spontaneous abortions and congenital malformations in infants delivered by women with diabetes, the incidence of the aforementioned pregnancy complications has increased by three- to fivefold (El-Sayed \& Lyell 2001, Baccetti et al. 2002). The ability of insulin to curtail delays in oocyte meiotic maturation caused by type 1 diabetic insults has been confirmed in studies 
from several different laboratories (Colton et al. 2002, Kim et al. 2007). Rates of GVBD and ovulation were significantly lower in streptozotocin (STZ)-treated mice than those in control mice. The delay in oocyte meiotic maturation was improved with insulin treatment during superovulation (Colton et al. 2002). Kim et al. (2007) also observed that insulin reverses the diabetes effect on in vitro maturation effects of the chronic diabetes-prone BioBreeding rats. However, we found that the ovulation rate of mice with severe hypoglycemia was lower than that of controls after insulin treatment. In addition, insulin treatment did not prevent or reverse vasculopathy and complications of type I diabetes mellitus (Waxman et al. 1993). The quality of life of patients with type I diabetes was affected as well.

Islet transplantation is a promising procedure for the treatment of patients with type I diabetes (Shapiro et al. 2000, Sabek et al. 2009). This treatment improved overall glucose homeostasis and retard and also reversed the progression of complications in patients with type I diabetes (Fiorina et al. 2003a, 2003b, 2005, Venturini et al. 2006, Thompson et al. 2008). However, little is known about the effects of this treatment on compromised oocyte competence due to diabetes. We therefore hypothesized that islet transplantation can prevent the damages to oocytes induced by diabetes. The objective of this study was to test this hypothesis. Therefore, we assessed the number of ovulated oocytes, spindle morphology, karyotypic status, relative expression of Mad2 and Bub1, and susceptibility of oocytes to activating stimuli, after islet transplantation. In order to avoid immunological rejection, we performed syngraft islet transplantation (islet transplantation for short).

\section{Results}

\section{Effects of islet transplantation on weight and blood glucose}

As shown in Fig. 1, we kept track of weight and blood glucose of insulin-treated and islet-transplanted mice closely. We observed that insulin-treated mice slightly increased in weight after insulin treatment, while islettransplanted mice first went through weight loss because of the operation and then gained weight progressively (Fig. 1A). We detected blood glucose every day. As shown in Fig. 1B, insulin-treated mice sometimes went through hyperglycemic or hypoglycemic episodes $2 \mathrm{~h}$ after insulin treatment every day. Islet transplantation normalized and stabilized the blood glucose, maintaining the overall glucose homeostasis.

\section{Effects of islet transplantation on ovulation}

To determine whether islet transplantation affects the number of ovulated oocytes, we set up four groups: control, diabetic, insulin-treated, and islet-transplanted

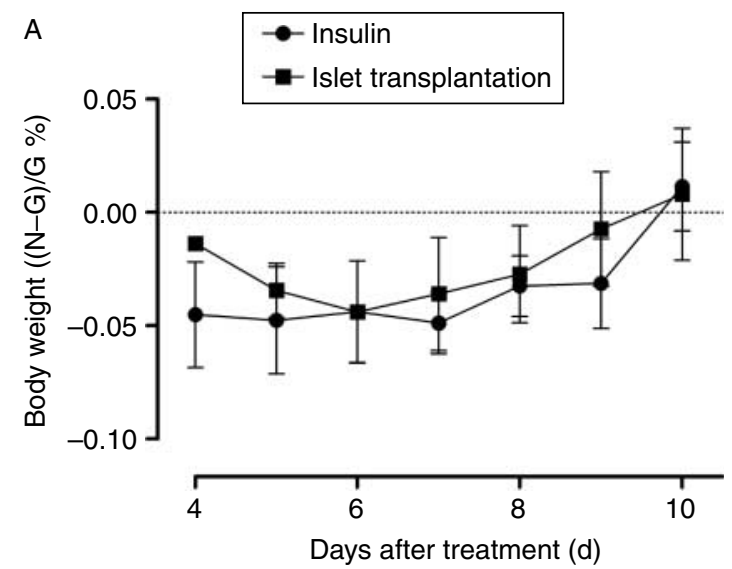

B

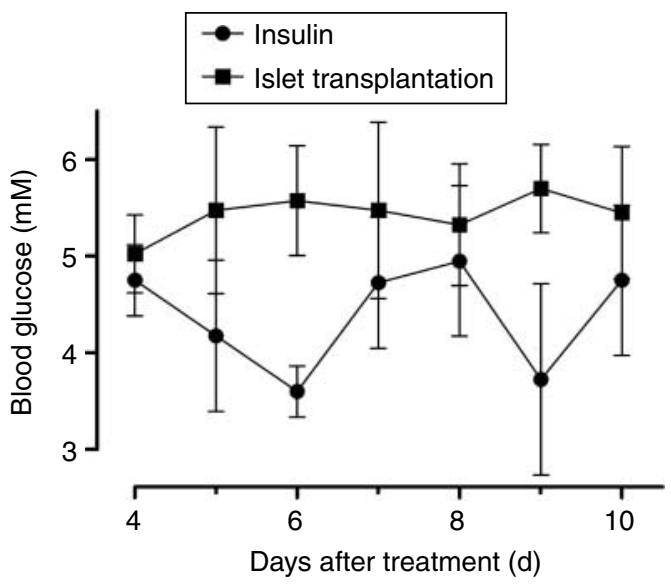

Figure 1 The weight and blood glucose of insulin-treated and islettransplanted mice since 4 days after STZ injection. (A) The weight of insulin-treated and islet-transplanted mice, shown as body weight $((\mathrm{N}-\mathrm{G}) / \mathrm{G}, \%)$. The letter $\mathrm{N}$ represented the weight that we detected every day, and the letter $G$ represented the weight at day 0 . (B) The blood glucose of insulin-treated and islet-transplanted mice.

groups. In all groups, the oocytes were retrieved from oviductal ampullae after superovulation with pregnant mare serum gonadotropin (PMSG) and human chorionic gonadotropin (hCG; Fig. 2). We obtained about one-half as many oocytes from diabetic mice as from control mice (Fig. 3). There was no dramatic difference between insulin-treated and diabetic mice. The number of oocytes obtained from islet-transplanted mice was similar to that obtained from control mice. Overall, these results suggest that islet transplantation reversed the effects of maternal diabetes on the number of ovulated oocytes, while insulin treatment could not.

\section{Effects of islet transplantation on spindle morphology}

To test for the possible effects of islet transplantation on the organization of the spindle and chromatin in MII oocytes, ovulated MII oocytes were immunolabeled with $\alpha$-tubulin antibody to visualize the spindle and were co-stained with propidium iodide (PI) to visualize 

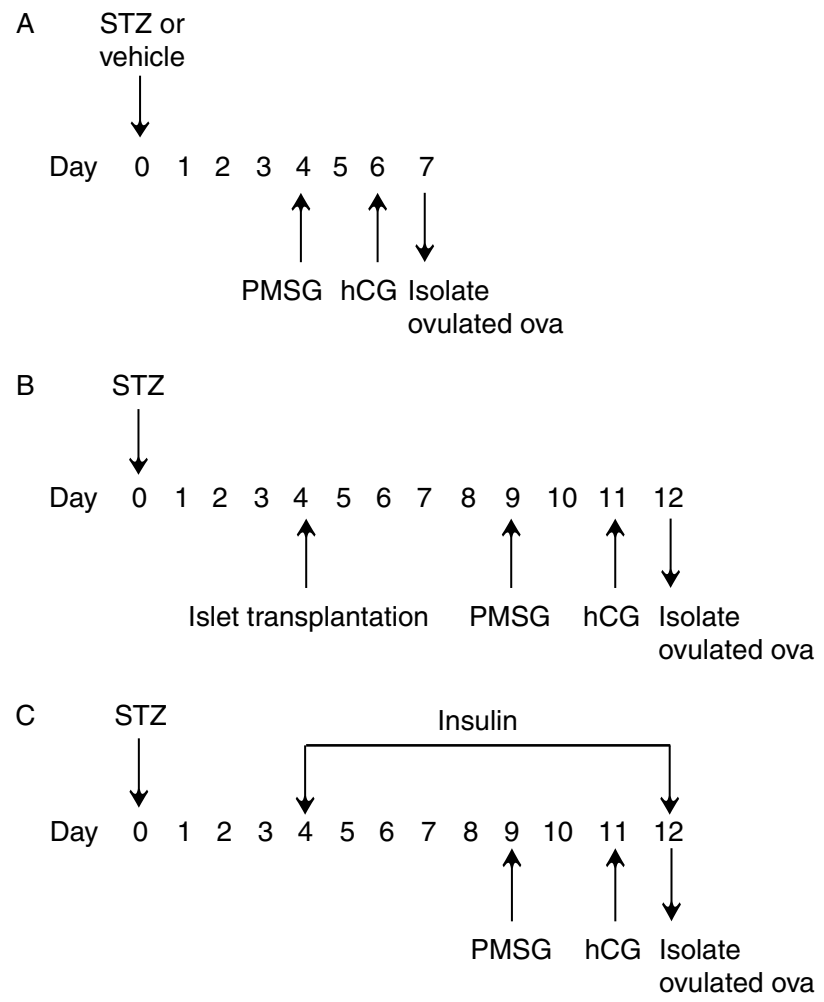

Figure 2 Schematic illustration of diabetes induction, islet transplantation, insulin treatment, and oocyte collection. (A) Diabetes induction. Female mice received an injection of $190 \mathrm{mg} / \mathrm{kg}$ streptozotocin (STZ) on day 0. Superovulation began at day 4. Mice were killed and cumulus-oocyte complexes (COCs) were collected 3 days later. (B) Islet transplantation. Four hundred islets were transplanted under the kidney capsule of diabetic B6 mice. Superovulation began at day 9 Mice were killed and COCs were collected 3 days later. (C) Insulin treatment. $1 \mathrm{IU}$ insulin was injected s.c. into diabetic B6 mice for 7 successive days beginning 4 days after STZ administration. Superovulation began at day 7. Mice were killed and COCs were collected 3 days later.

chromosomes. By performing confocal scanning, we found that normal MII oocytes present a typical barrelshaped spindle, and that chromosomes are well aligned on the metaphase plate (Fig. 4A). In abnormal MII oocytes, spindle defects and chromosome misalignment were readily observed (Fig. 4B). Moreover, a high frequency of spindle defects $(17.1 \pm 1.56 \%)$ and chromosome misalignment $(9.8 \pm 2.41 \%)$ was observed in ovulated MII oocytes from diabetic mice compared with the control MII oocytes (Table 1). Conversely, only $5.2 \pm 1.17$ and $4.5 \pm 2.09 \%$ ova displayed disorganized spindle and chromosomes respectively in ovulated MII oocytes from islet-transplanted mice and did not differ from control mice. There was no dramatic difference between insulin-treated and islet-transplanted mice. These results indicate that both insulin treatment and islet transplantation could reverse the effects of maternal diabetes on the organization of spindles and chromatin in MII oocytes.

\section{Effects of islet transplantation on aneuploidy}

To further analyze the chromosome morphology of MII oocytes from islet-transplanted mice, we carried out chromosome spread experiments. Normal oocytes have a haploid complement of 20 chromosomes (Fig. 5A), but if the separation of homologous chromosomes or sister chromatids is incorrect during meiosis, then aneuploid oocytes are generated (Fig. 5B). Our analysis was restricted to hyperploidy, because it is less influenced by spreading conditions (Eichenlaub-Ritter \& Boll 1989, Cukurcam et al. 2003). Our results revealed a significant increase in the incidence of hyperploidy in ovulated oocytes from diabetic mice compared with the ovulated controls (Table 1). The rate of hyperploidy is dramatically reduced in insulin-treated mice compared with diabetic mice, but still significantly higher than in islet-transplanted and control mice. Consistent with the earlier results, in this study, we found that islet transplantation reversed the effect of maternal diabetes on aneuploidy in ovulated oocytes, while insulin treatment had partly reduced the negative influence of diabetes.

\section{Effects of islet transplantation on the relative expression of Mad2 and Bub1}

Real-time PCR analysis was used to determine the relative expression levels of Mad2 and Bub1 in ovulated oocytes from four groups. As shown in Fig. 6, the relative expression levels of Mad2 and Bub1 were significantly higher in diabetic mice than those in control mice, but there were no significant differences among the control, insulin-treated, and islet-transplanted groups. Overall, these results suggested that both insulin treatment and islet transplantation reversed the effects of maternal diabetes on the relative expression levels of Mad2 and Bub1.

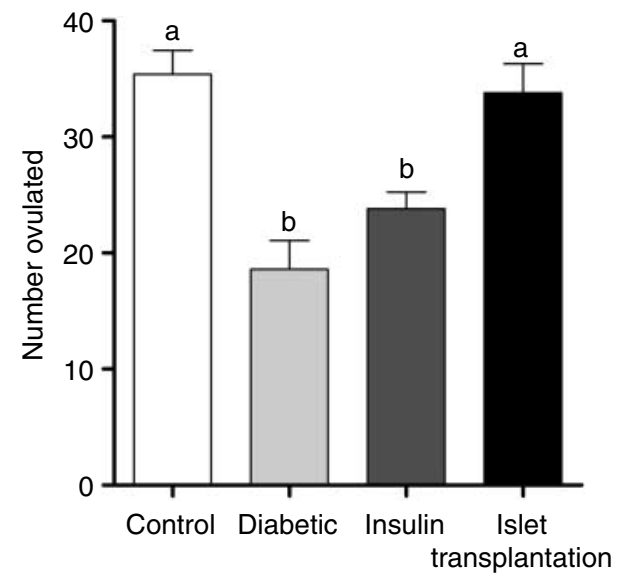

Figure 3 The number of ovulated oocytes in control, diabetic, insulin-treated, and islet-transplanted mice. Superovulated mice from four groups were killed $16 \mathrm{~h}$ after human chorionic gonadotropin (hCG) injection. Oocytes were then collected and counted. $N=10$ /group; ${ }^{a, b}$ values with a common superscript letter did not differ $(P>0.05)$. 

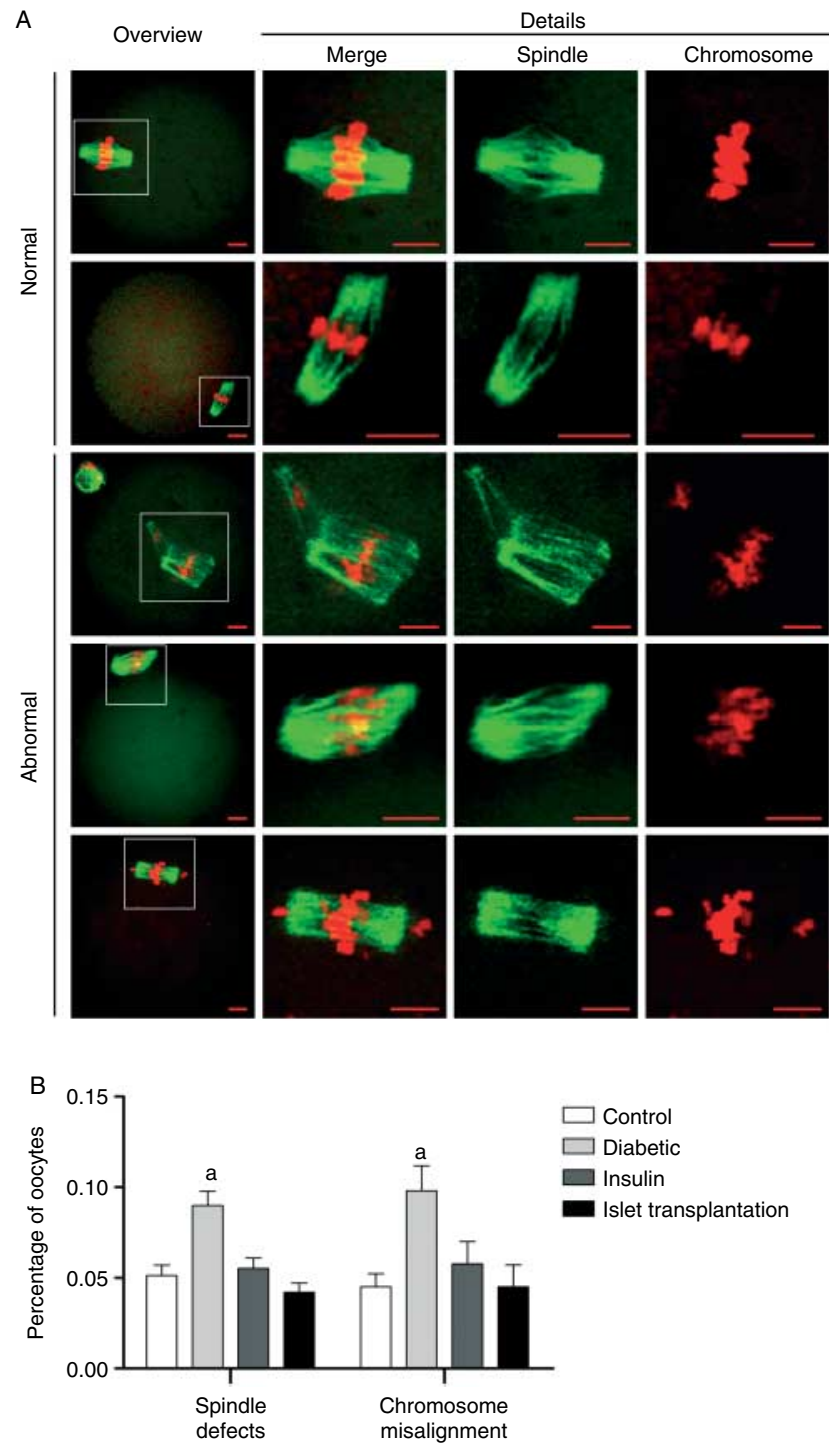

Figure 4 Spindle morphology of ovulated oocytes from control, diabetic, insulin-treated, and islet-transplanted mice. (A) Fluorescent photomicrographs depict normal and abnormal metaphase II (MII) oocytes. Green (Alexa Fluor 488) depicts the microtubules, and red (PI) depicts chromatin. Representative confocal sections are shown. (B) Quantification of ovulated MII oocytes with spindle defects and chromosome misalignment from control and diabetic mice. $N=5 /$ group; ${ }^{a}$ values with a common superscript letter represented a difference versus control $(P<0.05)$. Scale bars: $10 \mu \mathrm{m}$.

\section{Effects of islet transplantation on the susceptibility of oocytes to activating stimuli}

To determine whether islet transplantation affected embryo development after parthenogenetic activation of ovulated oocytes, the oocytes collected from four groups were activated by $\mathrm{SrCl}_{2}$ and subsequently cultured for embryo development. Our results showed that oocytes from the mice of these four groups developed into two-cell and four-cell embryos at a similar rate (Table 2). The blastocyst formation rates in diabetic mice were significantly higher than those in control mice, while the rates in insulin-treated and islettransplanted mice were similar to those for the corresponding controls.

\section{Discussion}

Mounting evidence has suggested that oocyte quality profoundly affects fertilization, early embryonic survival, establishment and maintenance of pregnancy, fetal development, and even adult disease (Krisher 2004, Sirard et al. 2006). Thus, investigation of ways to eliminate the effect of maternal diabetes on oocyte quality may lead to a fundamental solution for reproductive failure in diabetic females. As a treatment for diabetes, islet transplantation has been a hot topic for diabetes research fields (Shapiro et al. 2000, 2006). In this study, we investigate whether islet transplantation could reverse the effects of diabetes on oocytes.

Earlier work has shown that ovulation is compromised in diabetic animals (Kirchick et al. 1978, Garris et al. 1984, Powers et al. 1996, Colton et al. 2002), and we have confirmed this in the present study. Only approximately one-half as many ova were ovulated by diabetic mice compared with the control mice following a superovulation hormone regimen. However, the insulin-treated mice ovulated fewer compared with the control, while the islet-transplanted mice ovulated similarly to the control.

In order to further study on the effects of islet transplantation on diabetic oocytes, we examined other predictors of oocyte quality. Wang et al. (2009) observed an increased frequency of meiotic spindle defects, chromosome misalignment, and aneuploidy in oocytes from diabetic mice, which was confirmed by our laboratory results. In addition, our results revealed that insulin treatment and islet transplantation could normalize meiotic spindle and chromosome alignment, and hence affect the recovery of chromosome segregation.

In order to avoid aneuploidy, meiotic cells have developed a molecular mechanism called spindle checkpoint that underlies faithful chromosome separation in meiosis (Allshire 1997, Hwang et al. 1998, Musacchio \& Hardwick 2002). As shown in previous research and our results, maternal diabetes increased the aneuploidy rate; therefore, it is possible that maternal diabetes affects the oocyte spindle checkpoint. In support of this hypothesis, the relative mRNA expression levels of Mad2 and Bub1 were remarkably higher in ovulated oocytes from diabetic mice when compared with the control mice. In addition, our results revealed that there was no remarkable difference in the relative mRNA expression levels of Mad2 and Bub1 among the insulin-treated, islet-transplanted, and control mice. While spindle assembly was affected and Mad2 and Bub1 were activated in some of the oocytes from diabetic mice, spindle assembly was normal and Mad2 
Table 1 Islet transplantation reverses the effects of diabetes on the incidence of aneuploidy in ovulated oocytes.

\begin{tabular}{lccc}
\hline Group & Number of mice & Number of cells & Aneuploidy \\
\hline Control & 10 & 47 & $2(4.3 \%)^{\mathrm{a}}$ \\
Diabetic & 12 & 40 & $7(17.5 \%)^{\mathrm{b}}$ \\
Islet-transplanted & 10 & 42 & $2(4.8 \%)^{\mathrm{a}}$ \\
Insulin-treated & 10 & 45 & $4(8.9 \%)^{\mathrm{c}}$
\end{tabular}

$\overline{a, b, c}$ Values with a common superscript letter did not differ $(P>0.05)$.

and Bub1 were not activated in oocytes from islettransplanted mice.

It is worthwhile to note that Goud et al. (2006) pointed out that oocytes obtained from diabetic mice exhibited accelerated aging compared with those from nondiabetic mice, which involved altered spindle structure and premature loss of cortical granules as well as hardening of the zona pellucida. As one of the most prominent manifestations of aged oocytes is an increased susceptibility to activating stimuli (Kubiak 1989, Lan et al. 2004), we conducted an experiment to figure out whether oocytes from diabetic mice showed enhanced susceptibility to $\mathrm{SrCl}_{2}$. As expected, we identified that the rates of blastocyst formation in diabetic mice were significantly higher than those in the other groups, suggesting that diabetes enhanced the oocyte sensitivity to parthenogenetic activation. Conversely, the rates for blastocyst formation in islettransplanted mice were similar to those in the control mice, indicating that islet transplantation normalizes oocyte sensitivity to parthenogenetic activation.

Our results showed that insulin treatment could partly cure but not completely reverse the effects of diabetes on oocytes, which were contradictory to earlier studies (Colton et al. 2002, Kim et al. 2007). We speculate that there were two reasons for this contradiction. First, the length of exposure of the insulin-treated mice to the diabetic environment in this study was longer than that in earlier studies. In previous experiments, insulin was injected subcutaneously into mice for three successive days beginning 2 days after STZ administration before mice became diabetic (Colton et al. 2002), while in this study, the insulin injections began 6 days after STZ injection and the mice maintained diabetic condition for about 3 days. Perhaps the longer the exposure to a diabetic environment, the more difficult it is for the insulin treatment to restore ovulation. Secondly, although under close monitoring and glucose control, insulin-treated mice in this study easily caused hypoglycemia. In other words, our insulin treatment was akin to a clinical setting where diabetic females suffer from abnormal glucose concentration fluctuations despite dietary modifications and insulin treatment. Since oocytes are susceptible to glucose concentrationdependent perturbations in nuclear and cytoplasmic maturation, which lead to poor embryonic development post-fertilization (Sutton-McDowall et al. 2010), we assumed that abnormal glucose concentration fluctuations caused by insulin treatment could be partly responsible for decreased ovulation, as shown in Fig. 1.

In conclusion, our results strongly suggest that islet transplantation can reverse the effects of diabetes on oocytes by maintaining the overall glucose homeostasis. And one distinct benefit of islet cell transplantation was that it reduced the risk of oocyte defects being exacerbated by uncontrolled hypoglycemia. Thus, islet cell transplantation may have a specific role in patients who suffer from severe hypoglycemia with lack of warning on insulin therapy in humans. Remarkably, we performed syngraft islet transplantation to avoid immunological rejection. Unfortunately, this is not possible in diabetic humans who receive islet cell transplants and need anti-rejection therapies, as many

A
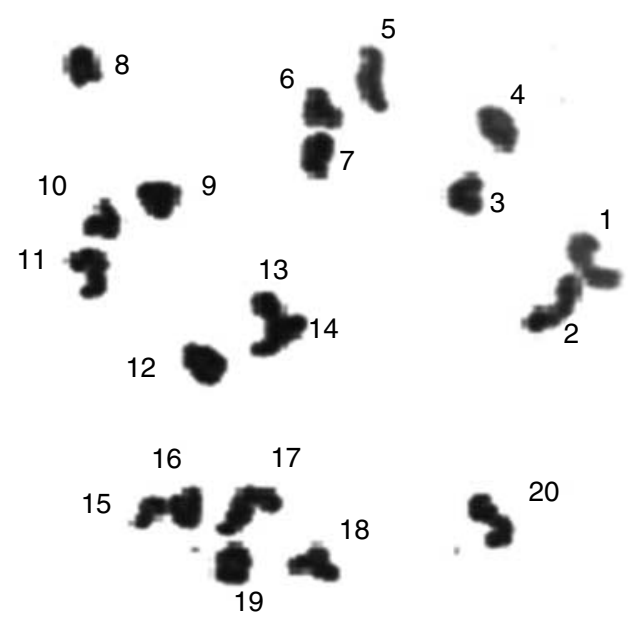

B
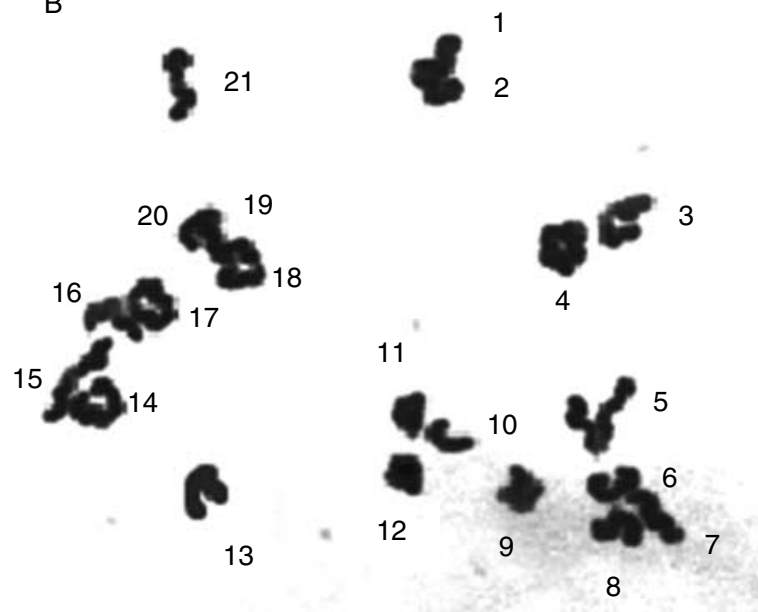

Figure 5 Chromosome spread of ovulated oocytes of control, diabetic insulin-treated, and islet-transplanted mice. Metaphase II (MII) oocytes were stained with $\mathrm{PI}$ and examined under a fluorescence microscope. Representative negative fluorescence micrographs: (A) oocytes with a normal haploid complement of 20 chromosomes and (B) oocytes with 21 chromosomes. 


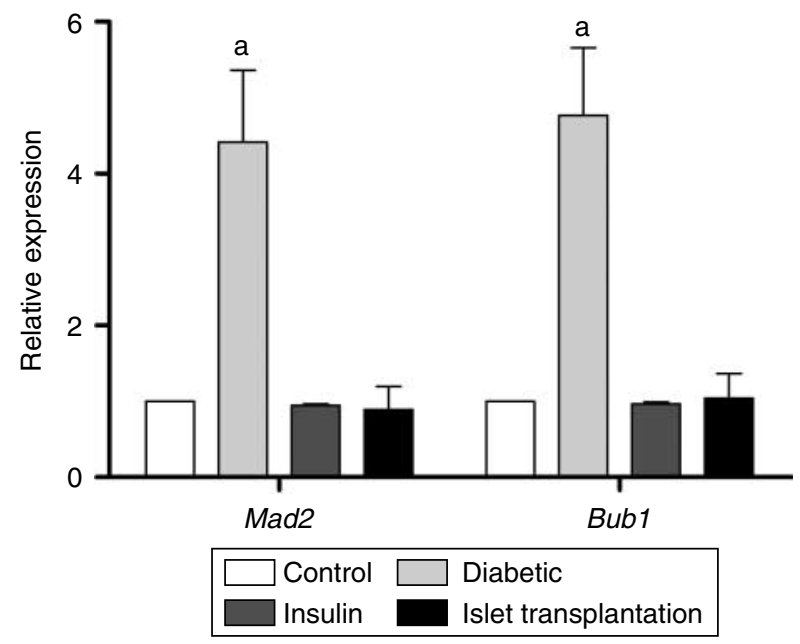

Figure 6 The relative mRNA expression levels of Mad2 and Bub1 in ovulated oocytes of control, diabetic, insulin-treated, and islet-transplanted mice, ${ }^{a}$ values with a common superscript letter represented a difference versus control $(P<0.05)$.

of these anti-rejection drugs are known to impair fertility and may cause oocyte defects. This is a major limitation to the extrapolation of these findings to the human situation. Although there are many difficulties with the practice of islet transplantation (Gaglia et al. 2005), with continued research into developing renewable islet sources and improved immunosuppression, this may become the most rational and practically feasible therapy for patients with type I diabetes.

\section{Materials and Methods}

Chemicals were purchased from Sigma Chemical Co., unless otherwise specified.

\section{Animals}

Female mice (C57BL/6), 6-8 weeks old, were maintained in a room with a $12 \mathrm{~h}$ light: $12 \mathrm{~h}$ darkness cycle, with the darkness starting from $1900 \mathrm{~h}$. The mice were obtained from Slac Laboratory Animal Co. Ltd. (Shanghai, China) and handled in accordance with the rules stipulated by the NIH publication 'Principles of Laboratory Animal Care'.

\section{Superovulation and oocyte retrieval}

To induce superovulation, C57BL/6 mice were given an i.p. treatment of 10 IU PMSG (Ningbo Sansheng Pharmaceutical Company, Ningbo, China) followed $48 \mathrm{~h}$ later by i.p. treatment of 10 IU hCG (Ningbo Sansheng Pharmaceutical Company). Superovulated mice were killed $16 \mathrm{~h}$ after hCG injection, and the oviductal ampullae were broken to release the cumulusoocyte complexes (COCs). The COCs were denuded of cumulus cells by pipetting in $\mathrm{M} 2$ medium containing $0.1 \%$ $(\mathrm{v} / \mathrm{v})$ hyaluronidase, and the oocytes were counted.

\section{Generation of diabetic mice and treatments}

A $180-220 \mathrm{mg} / \mathrm{kg}$ dose of STZ in $0.1 \mathrm{M}$ citrate buffer ( $\mathrm{pH} 4.4$ ) was injected i.p. to induce diabetes, as described previously (Wang et al. 2009). Control mice received an equal volume of the sodium citrate vehicle buffer $(0.01 \mathrm{mM}, \mathrm{pH} 4.4)$. Blood glucose was measured using a One Touch glucose analyzer (FreeStyle, Abbott). Diabetes onset was defined as two consecutive blood glucose measurements $>16.7 \mathrm{mM}$. The scheme of superovulation is shown in Fig. 2A.

For the islet transplantation group, transplantation was performed 4 days after STZ administration. Islet transplant was considered functional following two consecutive blood glucose measurements $<8 \mathrm{mM}$. The time of islet rejection was defined as the first day of two consecutive blood glucose measurements $>11.1 \mathrm{mM}$. After a week, mice were superovulated and killed (Fig. 2B).

For the insulin treatment group, $1 \mathrm{IU}$ insulin (Sanofi-Aventis Deutschland $\mathrm{GmbH}$, Frankfurt, Germany) was injected s.c. every $24 \mathrm{~h}$ into diabetic B6 mice for 7 successive days beginning 6 days after STZ administration. Glucose levels were monitored $2 \mathrm{~h}$ after the insulin injection to ensure that blood glucose returned to control levels. The scheme of superovulation is shown in Fig. 2C.

\section{Islet isolation, purification, and transplantation}

The donors and recipients were C57BL/6 mice. Donor islets were isolated and transplanted by kidney subcapsular injection as described previously (Xia et al. 2010). Briefly, the pancreas was perfused via bile duct cannulation with $3 \mathrm{ml}$ of $1.5 \mathrm{mg} / \mathrm{ml}$ collagenase $\mathrm{P}$ (Roche) and excised. The pancreas was incubated in a water bath at $37^{\circ} \mathrm{C}$, digested for $20 \mathrm{~min}$, and was then shaken vigorously in cold Hank's balanced salt solution (HBSS). The suspension was allowed to sediment and was washed three times in HBSS. Islets were sorted manually under a microscope, collected in vials of 600 islets, centrifuged at $92 \mathrm{~g}$ for $2 \mathrm{~min}$, and transplanted using a $1.2 \mathrm{~mm}$ diameter venflon (Becton Dickinson, Stockholm, Sweden) under the kidney capsule of diabetic mice.

\section{Immunofluorescence}

For spindle and chromosome analyses, oocytes were fixed with $4 \%(\mathrm{w} / \mathrm{v})$ paraformaldehyde for $30 \mathrm{~min}$ and then permeabilized with $0.5 \%(\mathrm{v} / \mathrm{v})$ Triton $\mathrm{X}-100$ for $20 \mathrm{~min}$. Followed by blocking in $1 \%(\mathrm{v} / \mathrm{v}) \mathrm{BSA}$-supplemented PBS for $1 \mathrm{~h}$, samples were incubated

Table 2 Effect of islet transplantation on embryo development after parthenogenetic activation of ovulated oocytes.

\begin{tabular}{lccc}
\hline Group & $\begin{array}{c}\text { Percentage of } \\
\text { two-cell }(\%)\end{array}$ & $\begin{array}{c}\text { Percentage of } \\
\text { four-cell }(\%)\end{array}$ & $\begin{array}{c}\text { Percentage of } \\
\text { blastocysts }(\%)\end{array}$ \\
\hline Normal & $77.0 \pm 3.8^{\mathrm{a}}$ & $66.3 \pm 3.8^{\mathrm{a}}$ & $49.0 \pm 12.2^{\mathrm{a}}$ \\
Diabetic & $81.3 \pm 4.6^{\mathrm{a}}$ & $76.3 \pm 4.4^{\mathrm{a}}$ & $58.3 \pm 1.2^{\mathrm{b}}$ \\
Islet-transplanted & $77.0 \pm 2.1^{\mathrm{a}}$ & $72.0 \pm 2.0^{\mathrm{a}}$ & $47.0 \pm 1.5^{\mathrm{a}}$ \\
Insulin-treated & $70.0 \pm 2.0^{\mathrm{a}}$ & $61.7 \pm 3.5^{\mathrm{a}}$ & $39.7 \pm 2.5^{\mathrm{a}}$ \\
\hline
\end{tabular}

$N=6 /$ group. ${ }^{\text {a,b }}$ Values with a common letter in their superscripts did not differ $(P>0.05)$. 
Table 3 The primer sequences used for qRT-PCR.

\begin{tabular}{ll}
\hline Primer name & \multicolumn{1}{c}{ Sequences } \\
\hline$\beta$-actin & Forward: 5'-CATCCGTAAAGACCTCTATGCCAAC-3' \\
& Reverse: 5'-ATGGAGCCACCGATCCACA-3' \\
Mad2 & Forward: 5'-AGTTCAGAAACTGGTGGTGGTCATC-3' \\
Bub1 & Reverse: 5'-TTCCAACAGTGGCAGAAATGTCA-3' \\
& Forward: 5'-ATTGACCATGCGACAGTGGAAG-3' \\
& Reverse: 5'-GTCATCCCATGGGTTCTCAACAG-3' \\
\hline
\end{tabular}

with Alexa Fluor 488 anti-alpha tubulin (1:50; Ebioscience, SanDiego, CA, USA) to visualize the spindle. Nuclear status was evaluated by staining with $10 \mathrm{mg} / \mathrm{ml} \mathrm{PI}$ in PBS for $10 \mathrm{~min}$. After extensive washing, samples were mounted on slides with anti-fluorescence fade medium (1,4-diazobicyclo-[2,2,2]-octane, DABCO). Finally, the samples were observed under a Zeiss confocal laser scanning microscope (FluoView FV1000, Olympus, Japan)

\section{Chromosome spread}

The oocytes were treated with $1 \%(\mathrm{w} / \mathrm{v})$ sodium citrate for $20 \mathrm{~min}$, individually transferred to a glass slide, and then fixed in situ with several drops of 3 parts methanol to 1 part acetic acid. After air-drying, the chromosomes were observed by fluorescence microscopy following staining with $10 \mathrm{mg} / \mathrm{ml} \mathrm{PI}$.

\section{Oocyte activation and embryo culture}

Oocytes were incubated in activating medium at $37^{\circ} \mathrm{C}$ in a humidified atmosphere with $5 \% \mathrm{CO}_{2}$. The activating medium was $\mathrm{Ca}^{2+}$-free Chatot-Ziomek-Bavister (CZB) supplemented with $10 \mathrm{mM} \mathrm{SrCl}_{2}$ and $5 \mu \mathrm{g} / \mathrm{ml} \mathrm{CB}$. The oocytes were incubated in activating medium for $6 \mathrm{~h}$ and then in $\mathrm{CZB}$ without $\mathrm{SrCl}_{2}$ at $37^{\circ} \mathrm{C}$ in a humidified atmosphere with $5 \% \mathrm{CO}_{2}$ in the air. Assessment of embryo development was performed at $24 \mathrm{~h}$ (two-cell stage), $48 \mathrm{~h}$ (four-cell stage), and $96 \mathrm{~h}$ (blastocysts) after the onset of activation.

\section{Quantitative real-time PCR}

Total RNA was isolated from oocytes using the RNeasy kit (Qiagen) according to the manufacturer's protocol. RT and quantitative real-time PCR (qRT-PCR) was performed using commercially available reagents (Toyobo, Osaka, Japan). The StepOne Real-Time PCR System (ABI, Carlsbad, CA, USA) was used to detect amplification, and $\beta$-actin was used as a normalizing control. The primer sequences used for the qRT-PCR are listed in Table 3.

\section{Statistical analysis}

At least four replicates were conducted for each treatment. Frequencies were arcsine transformed and analyzed with ANOVA, and a Duncan's multiple comparison test was used to locate differences. All analyses were performed using the GraphPad prism (GraphPad, Inc., La Jolla, CA, USA) software. Data are expressed as means \pm s.D., and $P<0.05$ was considered significant.

\section{Declaration of interest}

The authors declare that there is no conflict of interest that could be perceived as prejudicing the impartiality of the research reported.

\section{Funding}

This work was supported by a Joint Research Project of Health and Education Bureau, Fujian Province (WKJ2008-2-50).

\section{References}

Allshire RC 1997 Centromeres, checkpoints and chromatid cohesion. Current Opinion in Genetics \& Development 7 264-273. (doi:10.1016/ S0959-437X(97)80137-2)

Baccetti B, La Marca A, Piomboni P, Capitani S, Bruni E, Petraglia F \& De Leo V 2002 Insulin-dependent diabetes in men is associated with hypothalamopituitary derangement and with impairment in semen quality. Human Reproduction 17 2673-2677. (doi:10.1093/humrep/17.10.2673)

Becerra JE, Khoury MJ, Cordero JF \& Erickson JD 1990 Diabetes mellitus during pregnancy and the risks for specific birth defects: a populationbased case-control study. Pediatrics 85 1-9.

Chang AS, Dale AN \& Moley KH 2005 Maternal diabetes adversely affects preovulatory oocyte maturation, development, and granulosa cell apoptosis. Endocrinology 146 2445-2453. (doi:10.1210/en.2004-1472)

Colton SA, Pieper GM \& Downs SM 2002 Altered meiotic regulation in oocytes from diabetic mice. Biology of Reproduction 67 220-231. (doi:10.1095/biolreprod67.1.220)

Cukurcam S, Hegele-Hartung C \& Eichenlaub-Ritter U 2003 Meiosis-activating sterol protects oocytes from precocious chromosome segregation. Human Reproduction 18 1908-1917. (doi:10.1093/humrep/deg378)

Diamond MP, Moley KH, Pellicer A, Vaughn WK \& DeCherney AH 1989 Effects of streptozotocin- and alloxan-induced diabetes mellitus on mouse follicular and early embryo development. Journal of Reproduction and Fertility 86 1-10. (doi:10.1530/jrf.0.0860001)

Doblado M \& Moley KH 2007 Glucose metabolism in pregnancy and embryogenesis. Current Opinion in Endocrinology, Diabetes, and Obesity 14 488-493. (doi:10.1097/MED.0b013e3282f1cb92)

Eichenlaub-Ritter U \& Boll I 1989 Nocodazole sensitivity, age-related aneuploidy, and alterations in the cell cycle during maturation of mouse oocytes. Cytogenetics and Cell Genetics 52 170-176. (doi:10.1159/ 000132871)

El-Sayed YY \& Lyell DJ 2001 New therapies for the pregnant patient with diabetes. Diabetes Technology \& Therapeutics 3 635-640. (doi:10.1089/ 15209150152811270)

Fiorina P, Folli F, Bertuzzi F, Maffi P, Finzi G, Venturini M, Socci C, Davalli A, Orsenigo E, Monti L et al. 2003 a Long-term beneficial effect of islet transplantation on diabetic macro-/microangiopathy in type 1 diabetic kidney-transplanted patients. Diabetes Care 26 1129-1136. (doi:10.2337/diacare.26.4.1129)

Fiorina P, Folli F, Zerbini G, Maffi P, Gremizzi C, Di Carlo V, Socci C, Bertuzzi F, Kashgarian M \& Secchi A 2003b Islet transplantation is associated with improvement of renal function among uremic patients with type I diabetes mellitus and kidney transplants. Journal of the American Society of Nephrology 14 2150-2158. (doi:10.1097/01.ASN. 0000077339.20759.A3)

Fiorina P, Venturini M, Folli F, Losio C, Maffi P, Placidi C, La Rosa S, Orsenigo E, Socci C, Capella C et al. 2005 Natural history of kidney graft survival, hypertrophy, and vascular function in end-stage renal disease type 1 diabetic kidney-transplanted patients: beneficial impact of pancreas and successful islet cotransplantation. Diabetes Care $\mathbf{2 8}$ 1303-1310. (doi:10.2337/diacare.28.6.1303)

Gabbe SG \& Graves CR 2003 Management of diabetes mellitus complicating pregnancy. Obstetrics and Gynecology 102 857-868. (doi:10.1016/j.obstetgynecol.2003.07.001)

Gaglia JL, Shapiro AM \& Weir GC 2005 Islet transplantation: progress and challenge. Archives of Medical Research 36 273-280. (doi:10.1016/ j.arcmed.2005.03.014) 
Garris DR, Whitehead DS \& Morgan CR 1984 Effects of alloxan-induced diabetes on corpus luteum function in the pseudopregnant rat. Diabetes 33 611-615. (doi:10.2337/diabetes.33.7.611)

Goud AP, Goud PT, Diamond MP, Gonik B \& Abu-Soud HM 2006 Activation of the cGMP signaling pathway is essential in delaying oocyte aging in diabetes mellitus. Biochemistry 45 11366-11378. (doi:10.1021/ bi060910e)

Greene MF 1999 Spontaneous abortions and major malformations in women with diabetes mellitus. Seminars in Reproductive Endocrinology 17 127-136. (doi:10.1055/s-2007-1016220)

Hwang LH, Lau LF, Smith DL, Mistrot CA, Hardwick KG, Hwang ES, Amon A \& Murray AW 1998 Budding yeast Cdc20: a target of the spindle checkpoint. Science 279 1041-1044. (doi:10.1126/science.279. 5353.1041)

Kim K, Kim CH, Moley KH \& Cheon YP 2007 Disordered meiotic regulation of oocytes by duration of diabetes mellitus in BBdp rat. Reproductive Sciences 14 467-474. (doi:10.1177/1933719107306228)

Kirchick HJ, Keyes PL \& Frye BE 1978 Etiology of anovulation in the immature alloxan-diabetic rat treated with pregnant mare's serum gonadotropin: absence of the preovulatory luteinizing hormone surge. Endocrinology 102 1867-1873. (doi:10.1210/endo-102-6-1867)

Krisher RL 2004 The effect of oocyte quality on development. Journal of Animal Science 82 (E-Supplement) E14-E23.

Kubiak JZ 1989 Mouse oocytes gradually develop the capacity for activation during the metaphase II arrest. Developmental Biology 136 537-545. (doi:10.1016/0012-1606(89)90279-0)

Lan GC, Ma SF, Wang ZY, Luo MJ, Chang ZL \& Tan JH 2004 Effects of post-treatment with 6-dimethylaminopurine (6-DMAP) on ethanol activation of mouse oocytes at different ages. Journal of Experimental Zoology. Part A, Comparative Experimental Biology 301 837-843. (doi:10.1002/jez.a.62)

Lea RG, McCracken JE, McIntyre SS, Smith W \& Baird JD 1996 Disturbed development of the preimplantation embryo in the insulin-dependent diabetic BB/E rat. Diabetes 45 1463-1470. (doi:10.2337/diabetes.45. 11.1463)

Moley KH, Chi MM \& Mueckler MM 1998 Maternal hyperglycemia alters glucose transport and utilization in mouse preimplantation embryos. American Journal of Physiology 275 E38-E47.

Musacchio A \& Hardwick KG 2002 The spindle checkpoint: structural insights into dynamic signalling. Nature Reviews. Molecular Cell Biology 3 731-741. (doi:10.1038/nrm929)

Powers RW, Chambers C \& Larsen WJ 1996 Diabetes-mediated decreases in ovarian superoxide dismutase activity are related to blood-follicle barrier and ovulation defects. Endocrinology 137 3101-3110. (doi:10. 1210/en.137.7.3101)

Ratchford AM, Chang AS, Chi MM, Sheridan R \& Moley KH 2007 Maternal diabetes adversely affects AMP-activated protein kinase activity and cellular metabolism in murine oocytes. American Journal of Physiology. Endocrinology and Metabolism 293 E1198-E1206. (doi:10.1152/ ajpendo.00097.2007)
Sabek OM, Hamilton DJ \& Gaber AO 2009 Prospects for future advancements in islet cell transplantation. Minerva Chirurgica 64 59-73.

Sadler TW, Hunter ES III, Balkan W \& Horton WE Jr 1988 Effects of maternal diabetes on embryogenesis. American Journal of Perinatology $\mathbf{5}$ 319-326. (doi:10.1055/s-2007-999717)

Shapiro AM, Lakey JR, Ryan EA, Korbutt GS, Toth E, Warnock GL, Kneteman NM \& Rajotte RV 2000 Islet transplantation in seven patients with type 1 diabetes mellitus using a glucocorticoid-free immunosuppressive regimen. New England Journal of Medicine 343 230-238. (doi:10.1056/NEJM200007273430401)

Shapiro AM, Ricordi C, Hering BJ, Auchincloss H, Lindblad R, Robertson RP, Secchi A, Brendel MD, Berney T, Brennan DC et al. 2006 International trial of the Edmonton protocol for islet transplantation. New England Journal of Medicine 355 1318-1330. (doi:10. 1056/NEJMoa061267)

Sirard MA, Richard F, Blondin P \& Robert C 2006 Contribution of the oocyte to embryo quality. Theriogenology 65 126-136. (doi:10.1016/ j.theriogenology.2005.09.020)

Sutton-McDowall ML, Gilchrist RB \& Thompson JG 2010 The pivotal role of glucose metabolism in determining oocyte developmental competence. Reproduction 139 685-695. (doi:10.1530/REP-090345)

Thompson DM, Begg IS, Harris C, Ao Z, Fung MA, Meloche RM, Keown P, Meneilly GS, Shapiro RJ, Ho S et al. 2008 Reduced progression of diabetic retinopathy after islet cell transplantation compared with intensive medical therapy. Transplantation 85 1400-1405. (doi:10. 1097/TP.0b013e318172ca07)

Venturini M, Fiorina P, Maffi P, Losio C, Vergani A, Secchi A \& Del Maschio A 2006 Early increase of retinal arterial and venous blood flow velocities at color Doppler imaging in brittle type 1 diabetes after islet transplant alone. Transplantation 81 1274-1277. (doi:10.1097/ 01.tp.0000208631.63235.6a)

Wang Q, Ratchford AM, Chi MM, Schoeller E, Frolova A, Schedl T \& Moley KH 2009 Maternal diabetes causes mitochondrial dysfunction and meiotic defects in murine oocytes. Molecular Endocrinology 23 1603-1612. (doi:10.1210/me.2009-0033)

Waxman K, Soliman MH \& Nguyen KH 1993 Absorption of insulin in the peritoneal cavity in a diabetic animal model. Artificial Organs $\mathbf{1 7}$ 925-928. (doi:10.1111/j.1525-1594.1993.tb00404.x)

Xia J, Chen J, Shao W, Lan T, Wang Y, Xie B, Thorlacius H, Tian F, Huang R \& Qi Z 2010 Suppressing memory T cell activation induces islet allograft tolerance in alloantigen-primed mice. Transplant International 23 1154-1163. (doi:10.1111/j.1432-2277.2010.01106.x)

Received 31 August 2010

First decision 22 September 2010

Revised manuscript received 18 January 2011

Accepted 27 January 2011 